\title{
The Effect of Freezing and Hydrocolloids on the Physical Parameters of Strawberry Mass-Based Desserts
}

\author{
Sigita Boča ${ }^{1 *}$, Ruta Galoburda ${ }^{2}$, Imants Skrupskis ${ }^{1}$, Dace Skrupska ${ }^{3}$ \\ ${ }^{1}$ Department of Nutrition, LLU, Liela iela 2, Jelgava LV-3001, Latvia \\ ${ }^{2}$ Department of Food Technology, LLU, Liela iela 2, Jelgava LV-3001, Latvia \\ ${ }^{3}$ Department of Languages, LLU, Liela iela 2, Jelgava LV-3001, Latvia
}

\begin{abstract}
The aim of the study was to evaluate the effect of freezing, thickening and storage on the physical properties of the strawberry desserts made with addition of various hydrocolloids. The strawberry cultivars 'Polka', 'Honeoye', and 'Senga Sengana' harvested in Latvia were used in the study. The strawberries were processed in a blender for obtaining a homogenous mass. The strawberry mass was analyzed fresh and after storage at $-18{ }^{\circ} \mathrm{C}$. Both fresh and frozen strawberry mass samples with added gelatine, xanthan gum, and sodium carboxymethyl cellulose were whisked until obtaining dessert. For determination of the optimum hydrocolloid amount, sensory evaluation was done using a five-point hedonic scale. Moisture, soluble solids content, density, and $\mathrm{pH}$ of the product were determined. Apparent viscosity was measured using a rotational viscometer DV-III Ultra. Consistency of the dessert during its storage was evaluated using a texture analyser TA.XT.plus. The results of sensory evaluation allow concluding that in order to provide the most acceptable consistency, colour, and taste of strawberry dessert, the optimum quantity of carboxymethyl cellulose and xanthan gum to be added is $0.6 \%$ and that of gelatine is $6 \%$. During freezing, the soluble solids content and $\mathrm{pH}$ level decreased in the strawberry mass, whereas the addition of hydrocolloids increased these values. The moisture content in strawberry puree, in its turn, as a result of freezing increased under the influence of syneresis, but added hydrocolloids, on the contrary, decreased this influence. Also the viscosity and consistency of the strawberry puree prepared from the researched cultivars decreased under the influence of freezing, whereas the addition of hydrocolloids increased both the values, making the strawberry dessert firmer. The research suggests that strawberry dessert with gelatine had the most pronounced changes during storage, but strawberry dessert with added xanthan gum and carboxymethyl cellulose changed the least.
\end{abstract}

Key words: Strawberries, variety, hydrocolloids, apparent viscosity, consistency.

\section{Introduction}

Practice of the world shows that increasingly often the consumer chooses the products that can be used in nutrition without spending much time for their preparation (Marčenkova, 2010). Desserts from different products are a demanded kind of production chosen by a consumer. Use of fruit desserts in nutrition is one of the ways how to consume vitamins and minerals.

Strawberries are one of the most popular summer fruits with a very pleasant taste and aroma and an explicit colour and texture, and they are locally available in the spring-summer period (Blanda et al., 2009; Pelayo, Ebeler, \& Kader, 2003; Sturm, Koron, \& Stampar, 2003). Strawberries are one of the most widely consumed fruits both fresh and processed, and because of their corresponding economic and commercial influence, they are frequently the most widely studied fruits from agronomical, genomic and nutritional point of view (Kader et al., 2005; Tulipani, Marzban, Herndl, Laimer, \& Mezzetti, 2011).

A tendency is observed in Latvia to reduce the daily consumption of local fruits. It is essential to enlarge their availability in the market of Latvia all the year round, because for the time being fruit consumption in nutrition has a seasonal character (Slimību profilakses ..., 2010). It is important to reach long-term maintenance of the product with minimal changes in its chemical

* Corresponding author's email: sigita.boca@apollo.lv 
content and organoleptic parameters; therefore, scientific researches and practical measures are necessary to search progressive methods of storage and preservation, among which an important place is taken by the freezing of fruits and fruit processing products.

At present, freezing is already a well known and popular branch. Up to now, freezing of fresh fruits has been investigated but comparatively few researches have been carried out about the impact of freezing on the quality of the fruit processing products. Therefore, it is necessary to research new solutions for the usage of both fresh and frozen fruit processing products (Huang \& Chen, 2013; Kampuse, Seglina, \& Skrupskis, 2005; Skrupskis, Boca, Rucins, Rozenbergs, \& Iljins, 2011).

During freezing, water transforms into ice crystals, facilitating the emergence of intermolecular formations that are influenced by binding hydrogen, which is maintained during thawing, forming a spongy texture and releasing water as a result of syneresis (Sae-kang \& Suphantharika, 2006). This influence can be decreased by using adequate hydrocolloids. Thus, it is necessary to evaluate suitable hydrocolloids that could be used in low concentrations immediately after thawing the fruit puree (Sae-kang \& Suphantharika, 2006; Soma, Williams, \& Lo, 2009).

Food texture can be manipulated by the addition of hydrocolloids in processed food products. As a definition, hydrocolloid means particles of $10-1000 \mathrm{~nm}$ in diameter dispersing in water as a continuous phase (van Olphen \& Mysels, 1975). Alternatively, the term refers to polysaccharides and proteins (Williams \& Phillips, 2000) which are used in a variety of industrial sectors, including foods, to control and regulate such a colloidal state. Hydrocolloids exhibit multiple functionalities in foods, including thickening, gelling, water holding, dispersing, stabilizing, film forming, and foaming, and have been used as a texture modifier in almost every kind of processed food products, including mayonnaises, dressings, dessert jellies, ice creams, and so on. Hydrocolloids are excellent stabilisers for cream, ice cream, frozen dessert, and low calorie products, providing optimum viscosity, intensified aroma release, and control of ice crystals (McKenna, 2003; Sae-kang \& Suphantharika, 2006). Food polysaccharides are from various natural sources: agar and carrageenan - from seaweeds; guar gum and locust bean gum - from plant seeds; pectin - from citrus or apple peels; xanthan gum and gellan gum - from microorganisms; and chitin and chitosan - from animals (Funami, 2011).

Most of hydrocolloids perform their functions in high temperature, which is related to the heating of products. There is less those hydrocolloids whose activity takes place already in low temperature. Taking into consideration different types of thermal treatment, such as pasteurisation and freezing used in fruit processing, as well as evaluation of the particular hydrocolloids, it has been found that xanthan gum, carboxymethyl cellulose and gelatine are suitable both in low and high temperatures. The task of hydrocolloids in fruit processing industry is to provide the pleasant texture of fruits for the consumer during fruit production and transportation (Bourne, 2002; Cepeda \& Gomez, 2002). Hydrocolloids can also be used to influence heat stability and filling properties in confectionery, thermo-reversibility in pastry glazing, and substitution of starch both in yogurt fruit products and pastry fillings, as well as in low calorie fruit desserts.

There are several advantages of using hydrocolloids, which are important for both the producer and the consumer. Their usage extends the possibilities of consumers' choice, because it enlarges the assortment of products, and already familiar products obtain new, improved properties. In order the consumer could receive a quality product, scientifically based researches are needed about the impact of the technological process on the production of quality fruit desserts. The aim of the study was to evaluate the effect of freezing, thickening, and storage on the physical properties of the strawberry desserts made with addition of various hydrocolloids.

\section{Materials and Methods \\ Raw materials}

Strawberries of the cultivars 'Polka', 'Honeoye', and 'Senga Sengana' at full ripeness stage, harvested at the end of June or at the beginning of July depending on the type of cultivar, were used for the study. The strawberry cultivar 'Polka' is one of the most popular ones in Latvia. Its berries ripen relatively late and are used for various purposes. The cultivar 'Honeoye' is very productive, and it ripens medium early. Its berries are suitable for fresh consumption, desserts, and freezing. The early cultivar 'Senga Sengana' is widely grown in Latvia, and its berries are used both fresh and processed. 
After harvesting, the strawberries were sorted, cleaned, washed, processed in a HR 2000/70 blender (Philips, China) until obtaining a homogenous mass, and placed into $200-\mathrm{ml}$ plastic vessels. The prepared mass was used for preparation of the dessert - fresh (just after preparation) and frozen (frozen at $-25 \pm 2{ }^{\circ} \mathrm{C}$ for $20 \mathrm{~h}$, stored in a frozen condition at $-18 \pm 2{ }^{\circ} \mathrm{C}$ for three months, thawed for $16 \mathrm{~h}$ till the product temperature reached $+4 \pm 2{ }^{\circ} \mathrm{C}$; further in the text - frozen puree).

\section{Preparation of strawberry dessert}

Strawberry puree with added hydrocolloid is classified as a dessert. Hydrocolloids xanthan gum KELTROL (CP Kelco A. Huber Company, USA), carboxymethyl cellulose CEKOL (CP Kelco $A$. Huber Company, USA), and gelatine (Latplanta, Latvia) were added to the raw material - fresh and frozen strawberry puree. The hydrocolloids were used as a thickener, stabilizer, and dispersant in the strawberry dessert. At low concentrations, they impart a high solution viscosity and hydrate in most water-based systems, because they are completely soluble in both hot and cold mass. The xanthan gum $(0.6 \%$ of sample mass) and sodium carboxymethyl cellulose $(0.6 \%)$ were added in a powder form during whisking, while gelatine was swollen and dissolved in water before adding to the sample. The strawberry puree sample with gelatine additive contained $6 \%$ of gelatine and $32 \%$ of water. The amounts of additives were established after sensory evaluation of the experimental samples. Both fresh and frozen strawberry mass samples with the hydrocolloids were whisked at $1140 \mathrm{rpm}$ for $5 \mathrm{~min}$.

For determination of the optimum hydrocolloid amount, dessert samples were prepared from a previously frozen strawberry (cultivar 'Polka') puree with different hydrocolloids at various concentrations. The following amounts of hydrocolloids were used for preparation of the experimental samples:

- xanthan gum KELTROL (XG) - 0.5\%, 0.6\%, $0.7 \%$, and $0.8 \%$ from the product mass;
- carboxymethyl cellulose CEKOL (CMC) $0.5 \%, 0.6 \%, 0.7 \%$, and $0.8 \%$ from the product mass;

- gelatine $(\mathrm{G})-5.0 \%, 6.0 \%, 7.0 \%$, and $8.0 \%$ from the product mass.

\section{Sensory evaluation of strawberry dessert}

Sensory evaluation was completed at the primary school "Taurenitis" in Jurmala, Latvia, in order to take into account the opinion of school children as potential consumers of strawberry desserts. Totally, 50 children took part in the evaluation, among them 32 boys and 18 girls. The average age of evaluators was nine years. The children evaluated the dessert samples (not exceeding 100 grams) prepared from a previously frozen strawberry puree with different hydrocolloids at various concentrations. The frozen strawberry puree with no added hydrocolloids was used as a control sample.

The degree of liking of the dessert taking into account its sensory properties (consistency, taste, and colour) was evaluated using a five-point hedonic scale ( 5 - like very much; 1 - dislike very much), which corresponds to the facial expressions displayed in the evaluation sheet (Fig. 1) as described by Stone \& Sidel (2004).

\section{The methods for evaluation of physical and chemical properties}

For measurement of soluble solids content, an ATAGO N20 digital refractometer (Atago Co., Ltd, Japan) was used according to ISO 2173:2003.

pH was determined using a Jenway $\mathrm{pH}$ meter 3510 (Jenway, UK) according to the standard LVS EN 1132 "pH Determination of Fruit and Vegetable Juice".

The moisture content was analysed gravimetrically according to GOST 28561-90 using a Precisa 205 ASCS analytical balance (Precisa Gravimetrics $A G$, Switzerland) with weighing precision $0.0001 \mathrm{~g}$, and a Binder drying kiln (Binder $G m b h$, Germany) with adjustable temperature. The

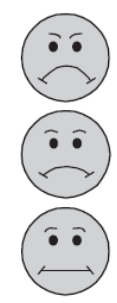

$$
\begin{aligned}
& \text { „dislike very much" } \\
& \text { „dislike a little” }
\end{aligned}
$$

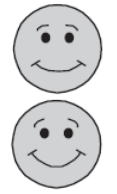

„like a little”

„not sure”

„like very much”

Fig. 1. Hedonic scale of facial expressions. 
sample was dried until unchanging weight, which was controlled by cooling and weighing the sample after certain periods of time.

The density $\left(\mathrm{kg} \mathrm{m}^{-3}\right)$ evaluation of strawberry mass and desserts was performed gravimetrically using a Precisa 260 analytical balance (Precisa Gravimetrics $A G$, Switzerland).

For apparent viscosity measurement, the samples of 100 grams of the product made from fresh and frozen strawberry puree with three different hydrocolloids were weighed into 150-ml glass beakers. The apparent viscosity was measured using a DV-III Ultra programmable rotational viscometer (Brookfield Engineering Laboratories, Inc., USA) at the temperature of $20.0 \pm 0.3{ }^{\circ} \mathrm{C}$. T-bar spindle at $5 \mathrm{rpm}$ was used for measuring viscosity. In order to provide a continuous contact of the spindle with the product, the Helipath Stand was used, which slowly raises and lowers the viscometer (at a rate of $7 / 8$ inches per minute) during the measurement. Test parameters were set in the software Rheocalc V2.6 as follows:

- SSN (set viscometer speed) - $5 \mathrm{rpm}$;

- WTI (wait for time interval) $-20 \mathrm{~s}$;

- DSP (single data point);

- LSC (loop count) - 10.

Triplicate measurements of the apparent viscosity of strawberry desserts were done immediately after preparation and each hour during a five-hour storage. The means and standard deviations are presented.

For the consistency analysis, the 100-ml samples of the product made from fresh and frozen strawberry purees with three different hydrocolloids were placed into 180-ml PET containers. The consistency of the samples was measured using a TA.XT.plus texture analyser (Stable Micro Systems Ltd., Surrey, UK). An aluminium cylinder P/25 (25 mm dia.) was used for the measurement. The pre-test speed was $1 \mathrm{~mm} \mathrm{~s}^{-1}$; test speed $-1 \mathrm{~mm} \mathrm{~s}^{-1}$; post-test speed $-10 \mathrm{~mm} \mathrm{~s}^{-1}$; distance $-25 \mathrm{~mm}$. The maximum force applied to the cylinder to move for $25 \mathrm{~mm}$ into the dessert layer was calculated from six independent measurements and was considered as the consistency of strawberry mass and dessert. The strawberry consistency was evaluated daily during five days of storage.

\section{Statistical analysis}

The analysis of variance (ANOVA) was conducted using the Windows software SPSS (version 15.00). The significant differences between treatments were analyzed with the t-test and Tukey's test at a significance level $p<0.05$.

\section{Results and Discussions \\ Sensory evaluation of the effect of hydrocolloids}

Consistency, taste and colour were evaluated as the most important sensory attributes of strawberry dessert. Each property was evaluated using a five-point hedonic scale. The average values are presented in Table 1. The data analysis revealed significant differences $(p<0.05)$ among strawberry dessert samples regarding their consistency, taste, and colour. The samples with the highest scores were selected for further experiments.

The degree of liking of the consistency of the frozen strawberry puree was scored 3.22 (not sure) according to the hedonic scale. The addition of the smallest researched amount of hydrocolloid made a significant difference $(p<0.05)$ in the consistency, colour and taste of the tested dessert and the control sample (Table 1). The degree of consistency liking of samples with $0.5 \%$ of $\mathrm{XG}, 0.5 \%$ of $\mathrm{CMC}$, and $5 \%$ of $\mathrm{G}$ ranged between „like a little” and „like very much" (4.18, 4.07, and 4.51, respectively). Increased amounts of added hydrocolloid $(0.7 \%$ and $0.8 \%$ ) decreased the degree of consistency liking. Evaluating the samples which contained higher amounts of hydrocolloids $(0.7 \%$ and $0.8 \%)$, the evaluators revealed that the degree of colour liking decreased with the increase in the amount of addition. By increasing the added amount of gelatine ( $7 \%$ and $8 \%$ in strawberry dessert made from previously frozen puree, the taste of gelatine became stronger and even overpowered the strawberry taste, as a result decreasing the degree of strawberry dessert liking. In the scientific literature it is stated that when the rigidity of the gels increased, the air/gel partition coefficients decreased, the maximum in-nose volatile concentrations increased, the release rates decreased, the perceived thickness intensity increased, and the odour, sweetness and strawberry flavour intensities decreased (Boland, Delahunty, \& Vanruth, 2006).

The results of sensory evaluation allow concluding that in order to provide the most acceptable consistency, colour and taste of strawberry dessert, the optimum quantity of carboxymethyl cellulose and xanthan gum to be added is $0.6 \%$, but that of gelatine is $6 \%$.

\section{The content of soluble solids and moisture, and $\mathrm{pH}$}

In fresh strawberry puree, the content of soluble solids ranged between $8.54 \pm 0.13$ (cultivar

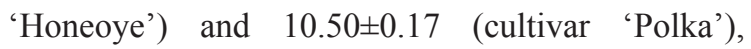


S. Boča et al. The Effect of Freezing and Hydrocolloids on Strawberry Mass-Based Desserts

Table 1

The degree of strawberry dessert liking evaluated regarding its sensory properties

\begin{tabular}{cllll}
\hline \multirow{2}{*}{ Sample } & \multicolumn{3}{c}{ Consory property } \\
\cline { 2 - 5 } & \multicolumn{2}{c}{ Control } & $3.22 \mathrm{a}$ & \multicolumn{2}{c}{ Taste } & Colour \\
\hline \multirow{3}{*}{$\mathrm{XG}$} & $0.5 \%$ & $4.18 \mathrm{~b}$ & $3.91 \mathrm{a}$ & $3.84 \mathrm{a}$ \\
\cline { 2 - 5 } & $0.6 \%$ & $4.69 \mathrm{~b}$ & $4.38 \mathrm{ac}$ & $4.51 \mathrm{ac}$ \\
\cline { 2 - 5 } & $0.7 \%$ & $4.42 \mathrm{bc}$ & $4.82 \mathrm{bcd}$ & $4.73 \mathrm{bcd}$ \\
\cline { 2 - 5 } & $0.8 \%$ & $3.60 \mathrm{ac}$ & $4.64 \mathrm{ad}$ & $4.69 \mathrm{bcd}$ \\
\hline \multirow{3}{*}{$\mathrm{G}$} & $5.0 \%$ & $4.51 \mathrm{~b}$ & $3.84 \mathrm{a}$ & $4.16 \mathrm{ad}$ \\
\cline { 2 - 5 } & $6.0 \%$ & $4.69 \mathrm{~b}$ & $4.53 \mathrm{acd}$ & $4.49 \mathrm{ac}$ \\
\hline & $7.0 \%$ & $4.18 \mathrm{bc}$ & $4.76 \mathrm{bce}$ & $4.71 \mathrm{bcd}$ \\
\hline \multirow{3}{*}{$\mathrm{CMC}$} & $8.0 \%$ & $3.47 \mathrm{ac}$ & $4.29 \mathrm{ae}$ & $4.33 \mathrm{ad}$ \\
\cline { 2 - 5 } & $0.5 \%$ & $4.07 \mathrm{bc}$ & $3.29 \mathrm{ad}$ & $3.87 \mathrm{a}$ \\
\cline { 2 - 5 } & $0.6 \%$ & $4.67 \mathrm{~b}$ & $4.38 \mathrm{ac}$ & $4.31 \mathrm{ac}$ \\
\cline { 2 - 5 } & $0.7 \%$ & $4.51 \mathrm{bd}$ & $4.78 \mathrm{bcd}$ & $4.76 \mathrm{bcd}$ \\
\hline & $0.8 \%$ & $3.80 \mathrm{acd}$ & $4.47 \mathrm{ad}$ & $4.64 \mathrm{ad}$ \\
\hline
\end{tabular}

Note. The values marked with the same letter in the same column for each hydrocolloid compared to the control sample did not significantly differ $(p>0.05)$ among each other.

which decreased during freezing on average by $6.16 \%$ (Table 2). With addition of hydrocolloids, the soluble solids content increased on average: in the dessert with XG - by $9.00 \%$ (fresh) and $17.22 \%$ (frozen), in the dessert with $\mathrm{G}-$ by $27.63 \%$ (fresh) and $27.64 \%$ (frozen), and in the dessert with CMC - by $6.46 \%$ (fresh) and $18.31 \%$ (frozen). The $\mathrm{pH}$ of fresh strawberry puree fluctuated from $3.24 \pm 0.02$ to $3.44 \pm 0.01$, during freezing it decreased to $3.18 \pm 0.01$ (cultivar 'Honeoye'), whereas the

The soluble solids and moisture content, and pH in strawberry dessert

\begin{tabular}{|c|c|c|c|c|c|c|c|}
\hline \multirow{2}{*}{\multicolumn{2}{|c|}{ Sample }} & \multicolumn{2}{|c|}{ Soluble solids, Brix $^{\circ}$} & \multicolumn{2}{|c|}{ Moisture, $\%$} & \multicolumn{2}{|c|}{$\mathrm{pH}$} \\
\hline & & fresh & frozen & fresh & frozen & fresh & frozen \\
\hline \multirow{3}{*}{ Control } & 'Polka' & $10.50 \pm 0.17$ & $9.98 \pm 0.15$ & $89.80 \pm 0.05$ & $90.70 \pm 0.07$ & $3.44 \pm 0.01$ & $3.32 \pm 0.01$ \\
\hline & 'Honeoye' & $8.54 \pm 0.13$ & $8.39 \pm 0.25$ & $90.70 \pm 0.08$ & $90.60 \pm 0.11$ & $3.24 \pm 0.02$ & $3.18 \pm 0.01$ \\
\hline & $\begin{array}{c}\text { 'Senga } \\
\text { Sengana' }\end{array}$ & $9.32 \pm 0.19$ & $8.24 \pm 0.14$ & $90.30 \pm 0.10$ & $90.50 \pm 0.12$ & $3.43 \pm 0.02$ & $3.32 \pm 0.03$ \\
\hline \multirow{3}{*}{$X G$} & 'Polka' & $11.27 \pm 0.26$ & $11.16 \pm 0.17$ & $89.50 \pm 0.04$ & $90.10 \pm 0.09$ & $3.59 \pm 0.02$ & $3.52 \pm 0.02$ \\
\hline & 'Honeoye' & $9.56 \pm 0.15$ & $10.82 \pm 0.21$ & $90.20 \pm 0.06$ & $90.40 \pm 0.08$ & $3.49 \pm 0.02$ & $3.41 \pm 0.02$ \\
\hline & $\begin{array}{c}\text { 'Senga } \\
\text { Sengana' }\end{array}$ & $10.34 \pm 0.19$ & $10.17 \pm 0.18$ & $89.90 \pm 0.08$ & $90.10 \pm 0.10$ & $3.56 \pm 0.01$ & $3.49 \pm 0.02$ \\
\hline \multirow{3}{*}{$\mathrm{G}$} & 'Polka' & $13.44 \pm 0.18$ & $12.79 \pm 0.19$ & $89.40 \pm 0.06$ & $90.00 \pm 0.07$ & $3.98 \pm 0.03$ & $3.91 \pm 0.03$ \\
\hline & 'Honeoye' & $12.69 \pm 0.18$ & $12.04 \pm 0.22$ & $90.10 \pm 0.05$ & $90.30 \pm 0.09$ & $3.90 \pm 0.02$ & $3.84 \pm 0.03$ \\
\hline & $\begin{array}{c}\text { 'Senga } \\
\text { Sengana' }\end{array}$ & $13.06 \pm 0.21$ & $11.95 \pm 0.24$ & $89.70 \pm 0.07$ & $89.90 \pm 0.08$ & $3.94 \pm 0.02$ & $3.87 \pm 0.03$ \\
\hline \multirow{3}{*}{$\mathrm{CMC}$} & 'Polka' & $11.08 \pm 0.09$ & $11.54 \pm 0.08$ & $89.60 \pm 0.09$ & $90.10 \pm 0.07$ & $3.75 \pm 0.02$ & $3.68 \pm 0.02$ \\
\hline & 'Honeoye' & $9.62 \pm 0.20$ & $10.70 \pm 0.13$ & $90.50 \pm 0.06$ & $90.60 \pm 0.10$ & $3.66 \pm 0.02$ & $3.59 \pm 0.02$ \\
\hline & $\begin{array}{c}\text { 'Senga } \\
\text { Sengana', }\end{array}$ & $9.62 \pm 0.12$ & $10.34 \pm 0.15$ & $90.10 \pm 0.04$ & $90.40 \pm 0.09$ & $3.71 \pm 0.02$ & $3.65 \pm 0.02$ \\
\hline
\end{tabular}




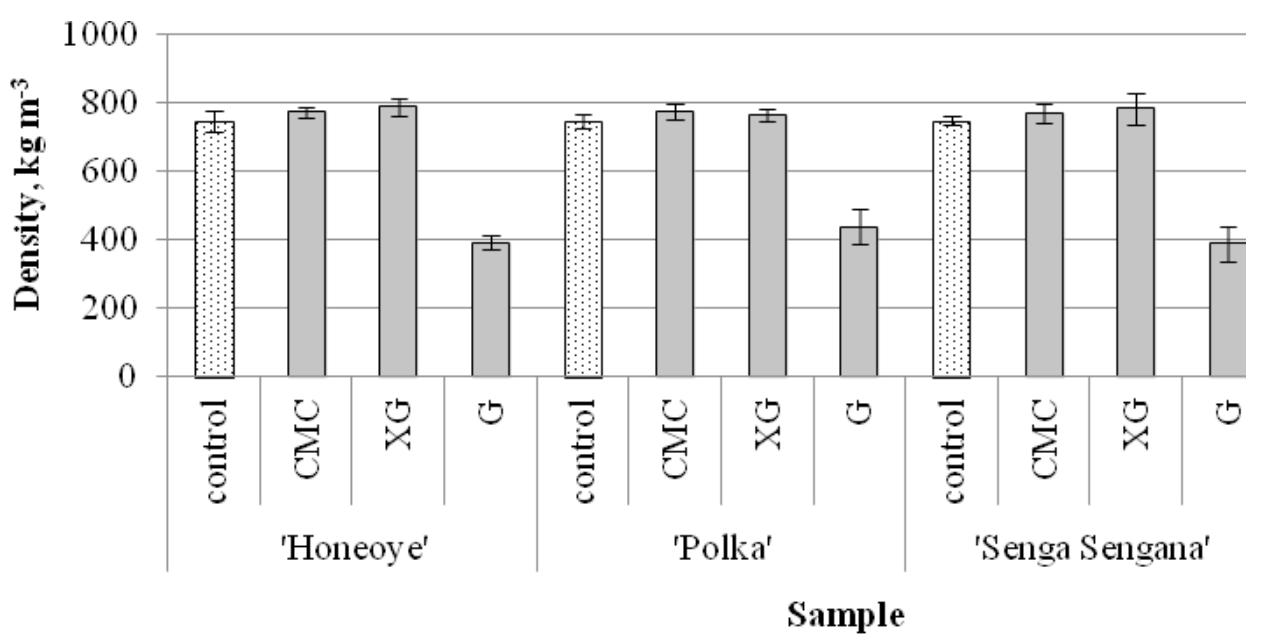

CMC - carb oxymethyl cellulose; XG - xanthan gum; G - gelatine

Fig. 2. The effect of hydrocolloids and whipping on the density of strawberry puree after frozen storage and adding of hydrocolloids.

addition of hydrocolloids increased the $\mathrm{pH}$ level it was the highest in the dessert from fresh puree with gelatine $-\mathrm{pH} 3.98 \pm 0.03$ (cultivar 'Polka').

The content of moisture in fresh strawberry puree ranged between $89.80 \pm 0.05$ and $90.70 \pm 0.08 \%$, and as a result of freezing it slightly increased, which could be explained by syneresis taking place during the freezing-thawing time (Sae-kang \& Suphantharika, 2006). With addition of hydrocolloids, the moisture content decreased, as hydrocolloids prevent syneresis and improve the properties of gel (Soma, Williams, \& Lo, 2009; Williams \& Phillips, 2000).

\section{Density}

Density of dessert is one of the most important physical parameters. The frozen strawberry puree of the corresponding cultivar was used for dessert preparation, therefore it was considered as a control sample. The research results suggest that there were no significant differences $(p=0.129)$ in the density of purees made from strawberries of the studied cultivars (Fig. 2). The average density of thawed puree was $750 \mathrm{~kg} \mathrm{~m}^{-3}$.

The addition of hydrocolloids and whipping affected the density of the finished product (dessert). If gelatine was added, the density of dessert significantly $(p<0.001)$ decreased compared to that of the puree used for dessert preparation. This means that the air, incorporated during whipping, decreases the density of the product mass, because as a result of intensive mixing, foams are forming and the process obtains physical character (Olivares,
Peirotti, \& Deiber, 2006; Tadros, Izquierdo, Esquena, \& Solans, 2004). The density decrease irrespective of the cultivar was $45.7 \%$ on average. The density of the sample made with gelatine was considerably lower than that in the desserts prepared using $\mathrm{CMC}$ or $\mathrm{XG}$ (Fig. 2). By adding hydrocolloids $\mathrm{XG}$ and $\mathrm{CMC}$, the density changes in the studied strawberry puree were not remarkable, which can be explained by the fact that hydrocolloids $\mathrm{XG}$ and $\mathrm{CMC}$ act as a thickener, stabiliser and dispersant (Sae-kang \& Suphantharika, 2006; Soma, Williams, \& Lo, 2009), but gelatine is a foam former (Olivares, Peirotti, \& Deiber, 2006). There were no significant differences in the density of desserts if $\mathrm{CMC}$ or XG was used for their preparation.

\section{The effect of freezing and hydrocolloids on the apparent viscosity of strawberry dessert}

The apparent viscosity of the fresh strawberry puree from the researched cultivars fluctuated from $38.98 \pm 1.02 \mathrm{~Pa} \mathrm{~S}$ ('Senga Sengana') to $44.67 \pm 1.16 \mathrm{~Pa} \mathrm{~s}$ ('Polka'). The viscosity of previously frozen and defrosted puree samples was almost twice lower than that of fresh strawberry puree of the same cultivar. The apparent viscosity of thawed samples ranged between 22.94 \pm 0.93 ('Senga Sengana') and 24.84 $\pm 1.60 \mathrm{~Pa}$ s ('Polka') (Fig. 3).

Data analysis showed that there was a significant difference between freshly made or previously frozen purees $(p<0.001)$. In the process of freezing products, during formation of ice crystals, the product is subjected to physical stress, and during the process of thawing, while melting of ice crystals, 


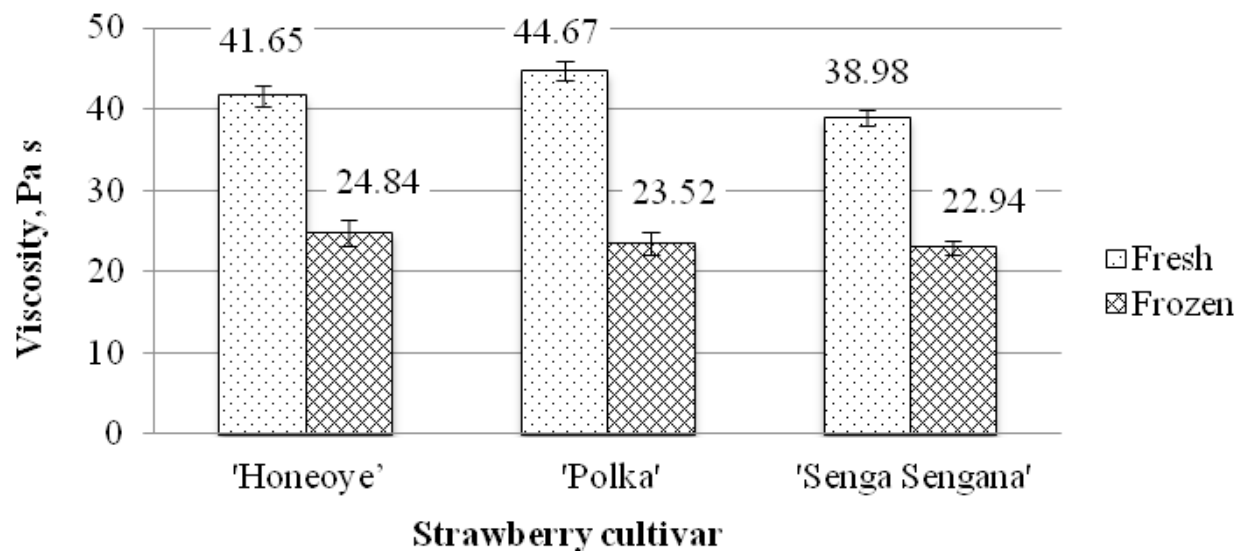

Fig. 3. Apparent viscosity of fresh and frozen strawberry puree samples.

the product obtains a softer consistency, which unfavourably influences the quality of the product (Sae-kang \& Suphantharika, 2006). Alongside with syneresis occurring during the process of freezing and thawing, the structure-mechanical properties of fruit processing products are influenced. This influence can be decreased by using adequate hydrocolloids. Thus, it is necessary to evaluate suitable hydrocolloids, which could be used in low concentration immediately after thawing of fruit puree, not influencing the taste, aroma and colour of the product (McKenna, 2003; Soma, Williams, \& Lo, 2009).

After addition of hydrocolloids (CMC, XG, and $G)$, the apparent viscosity of fresh and frozen strawberry puree increased (Fig. 4). A significant difference existed among dessert samples made with various hydrocolloids $(p<0.001)$, whereas the cultivar did not have a significant effect on the apparent viscosity of dessert ( $p=0.407$ ).

The viscosity of raw materials had changed the least in fresh strawberry puree with addition of the hydrocolloid CMC - from $41.63 \pm 1.05$ to $45.35 \pm 1.11 \mathrm{~Pa}$ s. The slight changes could be explained by the fact that in the case of a low $\mathrm{pH}$ ( $\mathrm{pH}$ of strawberry puree is 2.48-3.18), the added carboxymethyl cellulose forms products with a lower viscosity. Viscosity increased the most $(48.83 \pm 1.09-58.37 \pm 1.08 \mathrm{~Pa}$ s) with addition of the hydrocolloid XG to fresh strawberry puree compared to the control sample. The viscosity of xanthan gum solutions can only increase, not decrease, after adding an electrolyte, because it promotes helix formation and association. The stiffness of the xanthan chains gives rise to highly shear thinning rheological properties. Xanthan gum is stabile both

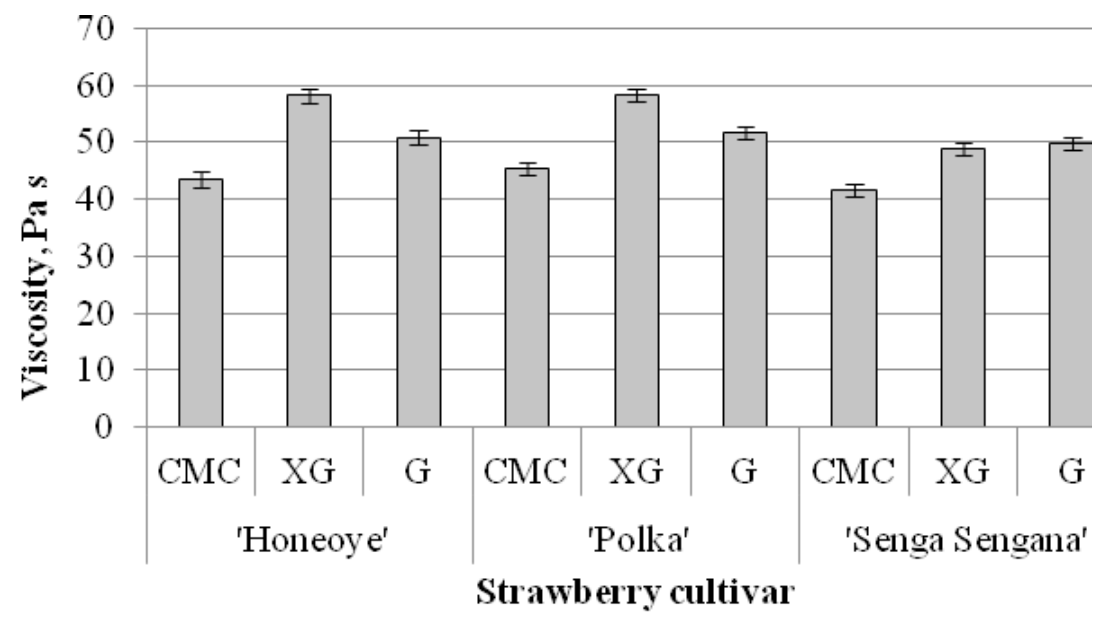

CMC - carboxymethyl cellulose; $\mathbf{X G}$ - xanthan gum; $\mathbf{G}$ - gelatine

Fig. 4. Apparent viscosity of strawberry dessert from fresh raw material. 
in a sour and alkaline medium, and it forms pseudoplastic dispersion in solutions (McKenna, 2003). Fresh strawberry puree with added gelatine had a lower viscosity immediately after preparation of the dessert, which can be explained by the fact that hydrophobic interaction in a cool diluted solution does not influence the compounds of the molecular chain. Olivares, Peirotti, and Deiber (2006) have observed that if the concentration is above the critical value (around $10^{-2} \mathrm{~g} \mathrm{~cm}^{-3}$ ), a transition from sol to gel takes place at a given maturation time provided the maturation temperature is set below that above which gel is not achieved.

Hydrocolloids had a similar effect on the viscosity of strawberry dessert prepared from frozen raw material compared to the control samples. The hydrocolloid CMC had the least effect on the viscosity of the dessert made from frozen strawberry puree of the cultivar 'Honeoye', whereas the addition of the hydrocolloid XG increased it the most - up to 53.44 \pm 1.32 Pa s (Fig. 5).

Hydrocolloids $\mathrm{CMC}$ and $\mathrm{XG}$ are suitable for structure formation of previously frozen raw materials as well as influence their rheological properties immediately after preparation of dessert. These hydrocolloids control food stability and prevent syneresis in defrosted products (McKenna, 2003). In our research, immediately after preparation of the dessert made from frozen strawberry puree with addition of gelatine, the viscosity increase differed depending on the cultivar because of the specific properties of this hydrocolloid - it has to be dissolved in water before use and its thickening time is comparatively much longer.

The viscosity of strawberry dessert was closely related to the soluble solids content, which is characterised by the correlation coefficient $(\mathrm{r}=0.831)$. In Figure 6, the regression line shows

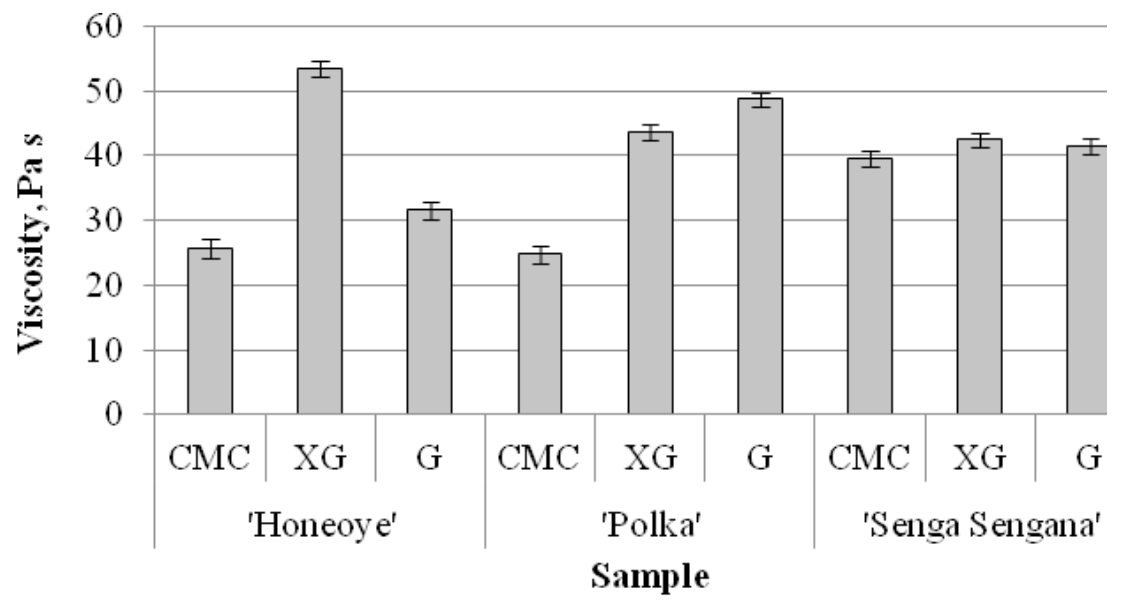

CMC - carboxymethyl cellulose; XG - xanthan gum; G - gelatine

Fig. 5. Apparent viscosity of strawberry dessert from frozen raw material.

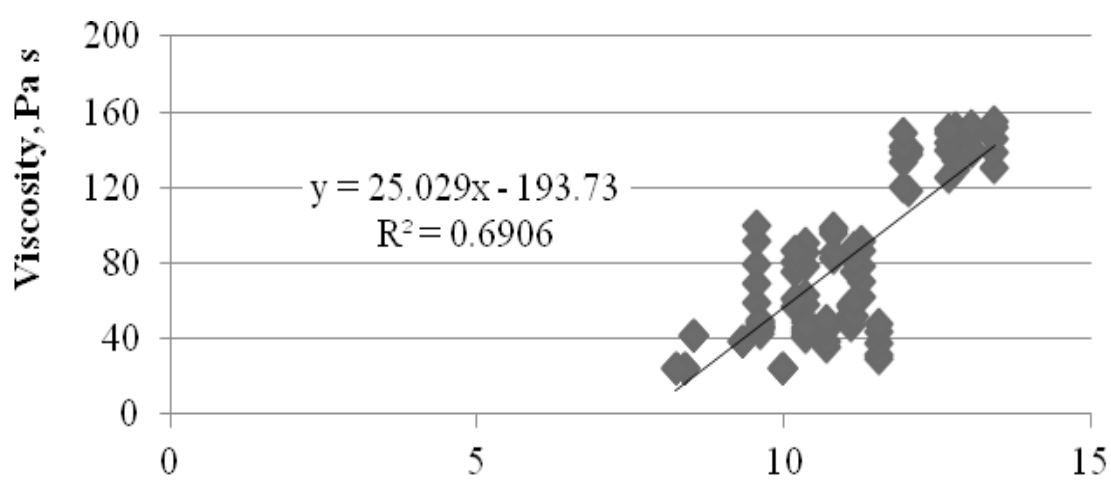

Soluble solids, Brix $^{\circ}$

Fig. 6. Correlation between the soluble solids content and viscosity in strawberry dessert. 
that the soluble solids content increases by 1 Brix $^{\circ}$ when the viscosity of strawberry dessert increases by $25.03 \mathrm{~Pa}$.

At the molecular level, gelation is the formation of a continuous network of polymer molecules, in which the stress-resisting bulk properties are imparted by a framework of polymer chains that extends throughout the gel phase (McKenna, 2003). Depending on the macroscopic behaviour of polymer systems, a distinction can be made between those gels that are free-standing as a consequence of the development of the threedimensional network, and the viscoelastic behaviour of the xanthan gum and carboxymethyl cellulose dispersions can be characterised as weak gels that are transient in time. They are characterised by a thin gellous network, which can be easily interrupted, when it is subjected to quite big stress (Williams \& Phillips, 2000). Therefore, when studying the influence of hydrocolloids on fresh and frozen strawberry puree, the viscosity changes were evaluated during five hours of storage after adding the hydrocolloids. Data showed that there were no significant differences $(p=0.407)$ among the viscosity of strawberry desserts from different cultivars; therefore, in Figure 7, the viscosity changes during five hours were reflected for the strawberry dessert only from one cultivar - 'Polka'.

The viscosity in the researched strawberry desserts just after the addition of hydrocolloids decreased compared to the viscosity of the puree used for production, which can be explained by the fact that there exist specific interactions among different biopolymers; in contrast, during five hours of storage, the viscosity gradually increased.

During storage (five hours), the viscosity of the strawberry dessert from cultivar 'Polka' with gelatine changed the most; in the dessert from fresh puree, the viscosity increased by $66.79 \%$; in the dessert from frozen puree, it increased by 67.86\%; and after adding the hydrocolloid CMC, the viscosity increased only slightly - by $22.33 \%$ (in the dessert from fresh puree) and by $47.92 \%$ (in the dessert from frozen puree). It should be noted that after a five-hour storage, the viscosity of the dessert made from frozen puree with a certain hydrocolloid became similar to the one made from fresh puree.

\section{The effect of freezing, hydrocolloids addition, and storage on the consistency of strawberry dessert}

After extending the strawberry dessert storage period till five days, which conforms to the production cycle in enterprises, the consistency changes in the dessert were evaluated as a quality parameter. The consistency of fresh and frozen strawberry puree from the researched cultivars ranged from $0.27 \pm 0.01 \mathrm{~N}$ ('Senga Sengana') to $0.31 \pm 0.01 \mathrm{~N}$ ('Polka'). The consistency of frozen

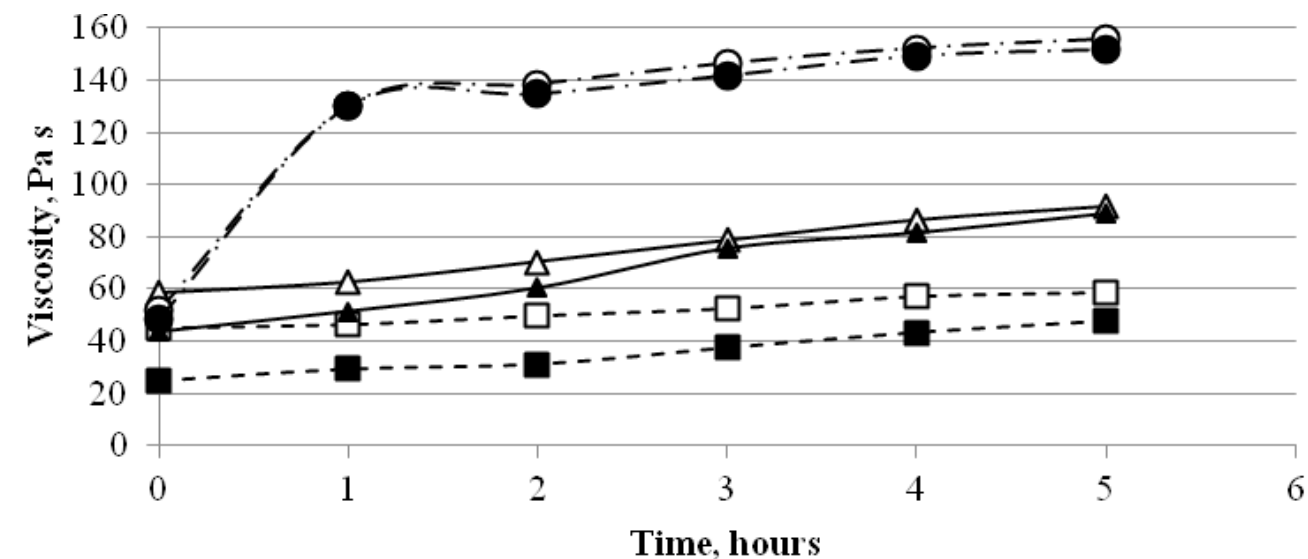

- - $\square$ - Fresh with CMC

$-\mathrm{O}-$ Fresh with gelatine

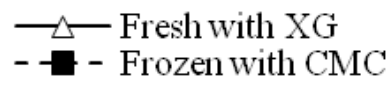

CMC-carboxymethyl cellulose; XG -xanthan gum; G-gelatine

Fig. 7. Changes in viscosity of strawberry dessert from cultivar 'Polka' during storage. 


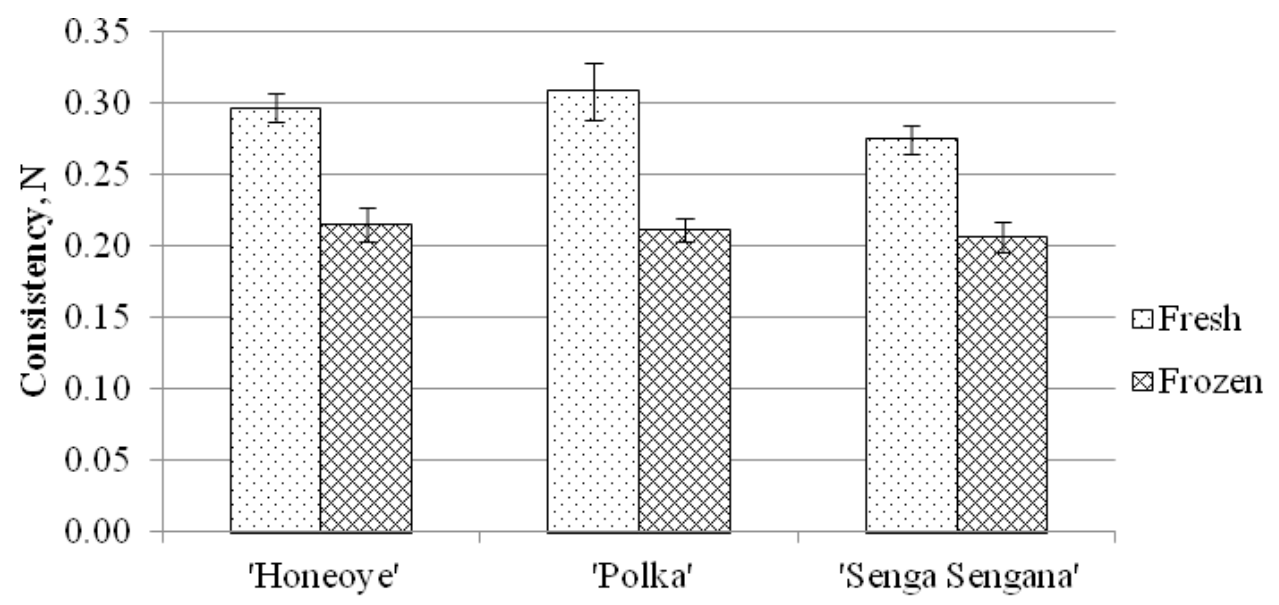

Strawberry cultivar

Fig. 8. Consistency of fresh and frozen strawberry puree.

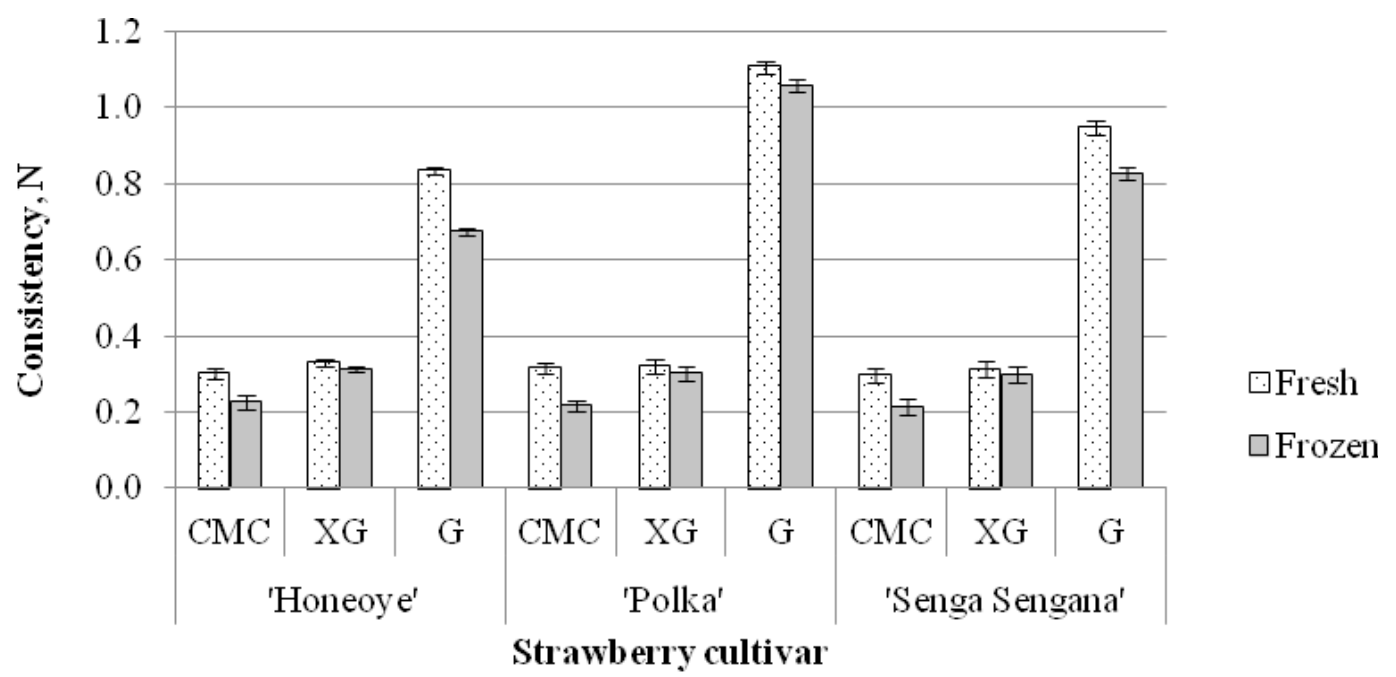

\section{CMC - carboxymethyl cellulose; XG - xanthan gum; $\mathbf{G}$ - gelatine}

Fig. 9. Consistency of strawberry dessert from fresh and frozen raw material.

strawberry puree decreased on average by $28.08 \%$ (Fig. 8).

The addition of hydrocolloids $\mathrm{XG}, \mathrm{CMC}$, and $\mathrm{G}$ increased the consistency of the purees - they became firmer (Fig. 9). Consistency of strawberry puree is related to the content of pectins and soluble solids. Desserts with added gelatine showed the greatest changes in product consistency during storage, which indicates the rigid consistency of the dessert during the last period of storage, which, in its turn, can have a negative impact on the consumers' opinion about the quality of the product. The samples with added hydrocolloids $\mathrm{CMC}$ and $\mathrm{XG}$ had the least changes, which points to the stable consistency of strawberry dessert during storage.
A close correlation existed between the consistency and soluble solids content of strawberry dessert $(\mathrm{r}=0.814)$. In Figure 10, the equation of regression line shows that consistency of the strawberry dessert increased by $0.163 \mathrm{~N}$ if the soluble solids content increased by 1 Brix $^{\circ}$.

Analysis of the consistency of strawberry dessert during a five-day storage showed that the cultivar 'Polka' dessert had the most pronounced changes in consistency (Fig. 11).

The most significant changes in consistency during storage were observed in the desserts made both from fresh and from frozen strawberry purees with gelatine: by $80.23 \%$ (dessert from fresh puree) and $79.64 \%$ (dessert from frozen puree). The 


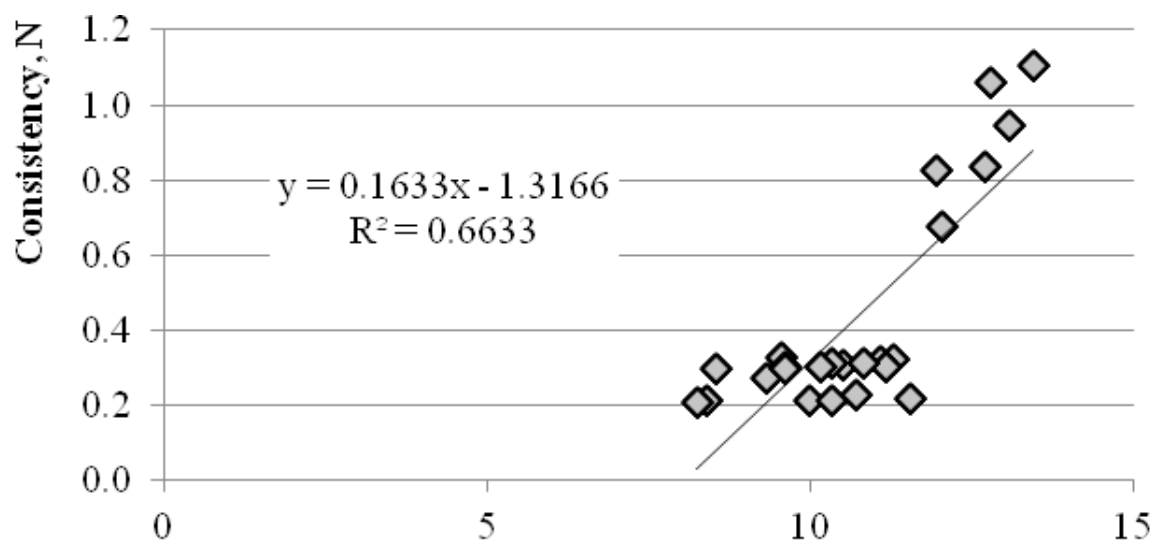

Soluble solids, Brix ${ }^{\circ}$

Fig. 10. Correlation between the soluble solids content and consistency in strawberry dessert.

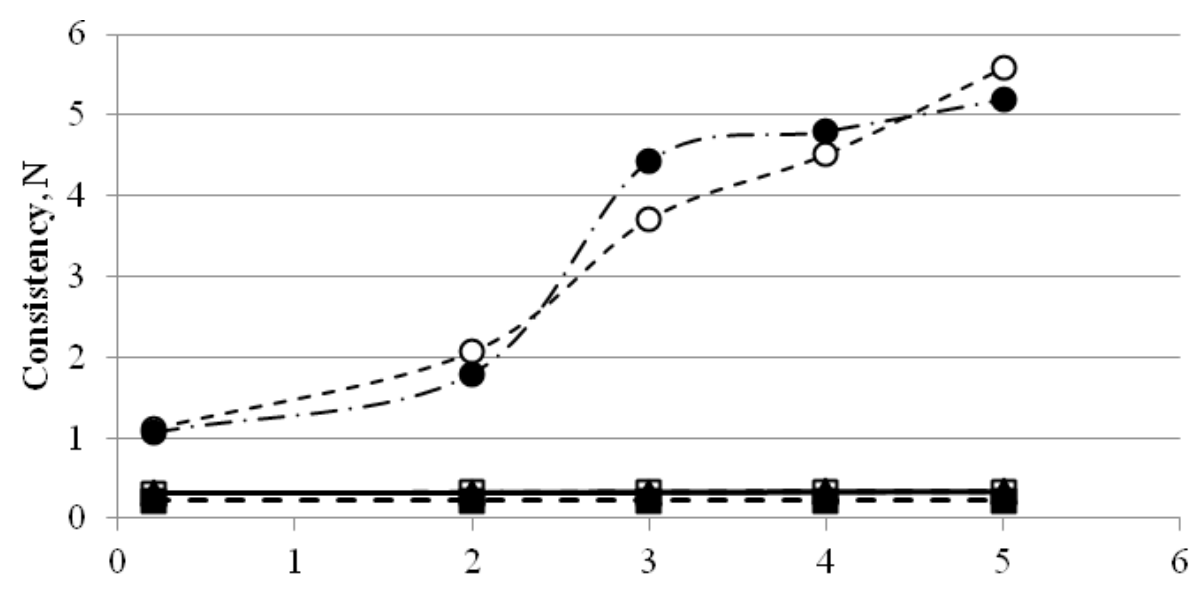

Time, days
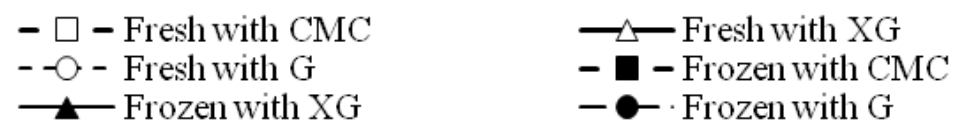

CMC -carboxymethyl cellulose; XG -xanthan gum; G-gelatine

Fig. 11. Consistency changes in strawberry dessert from cultivar 'Polka' during storage.

addition of hydrocolloids $\mathrm{CMC}$ and $\mathrm{XG}$, on the contrary, did not markedly influence the consistency of strawberry dessert. The remarkable consistency changes in the dessert with added gelatine during five-day storage indicated that they can influence the consumers' point of view about the quality of the product.

\section{Conclusions}

1. The optimum quantity of hydrocolloids to be added to strawberry puree is: $0.6 \%$ for each xanthan gum and carboxymethyl cellulose, and $6 \%$ for gelatine.

2. During freezing, the soluble solids content in strawberry puree decreased on average by
$6.16 \%$, whereas the addition of hydrocolloids increased its content and decreased the $\mathrm{pH}$ level to $3.18 \pm 0.01$. As a result of freezing, the moisture content in strawberry puree increased under the influence of syneresis, but the added hydrocolloids reduced this influence.

3. The moisture content in fresh strawberry puree fluctuated between $89.80 \%$ and $90.70 \%$ on average, which slightly increased under the influence of freezing. This could be explained by syneresis taking place during freezingthawing. The addition of hydrocolloids decreased the moisture content in the puree, because they prevent syneresis and improve gel properties. 
4. Gelatine added to fresh and frozen strawberry puree reduced its density almost twice, whereas xanthan gum and carboxymethyl cellulose influenced these parameters considerably less.

5. Data showed that there were no significant differences $(p=0.407)$ among the viscosities of strawberry desserts made from different cultivars. The viscosity and consistency values of strawberry purees decreased under the influence of freezing, whereas the addition of hydrocolloids increased these values, making the dessert firmer. The greatest changes during storage were observed in strawberry dessert with gelatine; the least changes were observed in strawberry dessert with xanthan gum and carboxymethyl cellulose.

\section{References}

1. Blanda, G., Cerretani, L., Cardinali, A., Barbieri, S., Bendini, A., \& Lercker, G. (2009). Osmotic dehydrofreezing of strawberries: Polyphenolic content, volatile profile and consumer acceptance. Food Science and Technology, 42, 30-36. Dx.doi.org/10.1016/j. lwt.2008.07.002.

2. Boland, A., Delahunty, C., \& Vanruth, S. (2006). Influence of the texture of gelatin gels and pectin gels on strawberry flavour release and perception. Food Chemistry, 96(3), 452-460. Doi: 10.1016/j.foodchem.2005.02.027.

3. Bourne, M. (2002). Food texture and viscosity. Concept and measurement (2nd ed.). San Diego [etc.]: Academic Press.

4. Cepeda, E., \& Gomez, R. (2002). Rheological characteristics of pimento puree: theoretical interpretation. Journal of Food Science, 67(7), 2734-2738. DOI: 10.1111/j.1365-2621.2002. tb08806.x.

5. Funami, T. (2011). Next target for food hydrocolloid studies: Texture design of foods using hydrocolloid technology. Food Hydrocolloids, 25(8), 1904-1914. Doi: 10.1016/j.foodhyd.2011.03.010.

6. Huang, Y., Ye, M., \& Chen, H. (2013). Inactivation of Escherichia coli O157:H7 and Salmonella spp. in strawberry puree by high hydrostatic pressure with/without subsequent frozen storage. International Journal of Food Microbiology, 160, 337-343. Dx.doi. org/10.1016/j.ijfoodmicro.2012.11.008.
7. Kader, A.A. (2005). Increasing food availability by reducing postharvest losses of fresh produce. Acta Horticulturae, 682, 2168-2177.

8. Kampuse, S., Segliṇa, D., \& Skrupskis, I. (2005). Changes of blackcurrant puree chemical components after frozen storage. Plodovodstvo, 17(2), 282-286.

9. Marčenkova, T. (2010). Microbiological criteria for ready-to-eat foods. Doctoral thesis for acquiring the Doctor's degree of Engineering sciences in the sector of Food Sciences. Jelgava: LLU.

10. McKenna, B.M. (Ed.). (2003). Texture in Food. Volume 1: Semi-solid foods. Boca Raton [etc.]: CRC Press; Cambridge: Woodhead Publishing Limited Ltd.

11. Olivares, M.L., Peirotti, M.B., \& Deiber, J.A. (2006). Analysis of gelatin chain aggregation in dilute aqueous solutions through viscosity data. Food Hydrocolloid, 20, 1039-1049. Dx.doi.org/10.1016/j.foodhyd.2005.10.019.

12. Pelayo, C., Ebeler, S.E., \& Kader, A.A. (2003). Postharvest life and flavor quality of three strawberry cultivars kept at $5{ }^{\circ} \mathrm{C}$ in air or air $+20 \mathrm{kPa} \quad \mathrm{CO}_{2}$. Postharvest Biology and Technology, 27, 171-183.

13. Sae-kang, V., \& Suphantharika, M. (2006). Influence of $\mathrm{pH}$ and xanthan gum addition on freeze-thaw stability of tapioca starch pastes. Carbohydrate Polymers, 65, 371-380. Dx.doi.org/10.1016/j.carbpol.2006.01.029.

14. Skrupskis, I., Boca, S., Rucins, M., Rozenbergs, V., \& Iljins, U. (2011). Research of half-finished frozen fruit and berry products. Proceedings of the 23rd IIR International congress of refrigeration Refrigeration for Sustainable Development, August 21-26, 2011 (p. 7). Prague: International Institute of Refrigeration.

15. Slimību profilakses un kontroles centrs. (2010). Latvijas iedzīvotāju veselību ietekmējošo paradumu pētījums (FINBALT monitorings): http://sabves.vec.gov.lv/Lists/DatuAvoti/Disp Form.aspx?ID=641

16. Soma, P., Williams, P., \& Lo, M. (2009). Advancements in non-starch polysaccharides research for frozen foods and microencapsulation of probiotics. Chinese Journal of Chemical Engineering, 3(4), 413-426. Doi: 10.1007/ s11705-009-0254-x. 
17. Stone, H., \& Sidel, J.L. (2004). Sensory Evaluation Practices. California: Tragon corporation.

18. Sturm, K., Koron, D., \& Stampar, F. (2003). The composition of fruit of different strawberry varieties depending on maturity stage. Food Chemistry, 83, 417-422. Dx.doi.org/10.1016/S03088146(03)00124-9.

19. Tadros, T., Izquierdo, P., Esquena, J., \& Solans, C. (2004). Formation and stability of nano-emulsions. Advances in Colloid and Interface Science, 108/109, 303-318. Dx.doi.org/10.1016/j.cis.2003. 10.023 .
20. Tulipani, S., Marzban, G., Herndl, A., Laimer, M., \& Mezzetti, B. (2011). Influence of environmental and genetic factors on health-related compounds in strawberry. Food Chemistry, 124, 906-913. Dx.doi.org/10.1016/j.foodchem.2010.07.018.

21. Van Olphen, H., \& Mysels, K.J. (Eds.) (1975). Physical chemistry: Enriching topics from colloid and surface science. La Jolla, CA: Theorex.

22. Williams, P.A., \& Phillips, G.O. (2000). Introduction to food hydrocolloids. In G.O. Phillips \& P.A. Williams (Eds.), Handbook of hydrocolloids (pp. 1-19). Cambridge: Woodhead Publishing Ltd.

\section{Acknowledgements}

This research was endorsed by the ESF "Support for doctoral studies in LLU", contract No. 2009/0180/1DP/1.1.2.1.2/09/IPIA/VIAA/017), and the EU "Scientific capacity building in fruitgrowing, forestry and information technology sectors, providing research on environmentally friendly growing strategies, product development and introduction aided by computer technologies", No. 2009/0228/1DP/1.1.1.2.0/09/APIA/VIAA/035. 